BMJ Paediatrics Open

\title{
Management of varicella in neonates and infants
}

\author{
Sophie Blumental, Philippe Lepage
}

To cite: Blumental S, Lepage P. Management of varicella in neonates and infants. BMJ Paediatrics Open 2019;3:e000433. doi:10.1136/ bmjpo-2019-000433

Received 3 January 2019 Revised 12 March 2019 Accepted 20 March 2019

\section{Check for updates}

(C) Author(s) (or their employer(s)) 2019. Re-use permitted under CC BY-NC. No commercial re-use. See rights and permissions. Published by BMJ.

Paediatric Infectious Diseases, Hôpital Universitaire des Enfants Reine Fabiola, Brussels, Belgium

Correspondence to Professor Philippe Lepage; lepagephil@skynet.be

\section{ABSTRACT}

In countries where vaccination is not implemented, varicella is a common ubiquitous disease offering a broad range of clinical presentations. Whereas motherto-child perinatal transmission of varicella zoster virus (VZV) can lead to disseminated life-threatening diseases in unimmunised newborns, postnatal acquisition will be generally a source of milder infections. The pattern and severity of the disease are known to be partly determined by the timing of VZV acquisition during pregnancy with the highest risk period located around delivery. Management of youngest children after contact with a varicella case remains difficult for clinicians not only because of unawareness of varicella natural history and risks factors for serious complications, but also because of the lack of consensus from experts available in the literature. This state of uncertainty often leads to overconsumption of healthcare resources with systematic hospitalisation and unjustified antiviral intravenous therapies. After a concise literature review, this article proposes pragmatic recommendations considering newborns in various scenarios following a contact with VZV, taking into account the timing and mode of virus transmission, the maternal immunological status, the baby's gestational age and the presence of other underlying conditions.

\section{INTRODUCTION}

Varicella is a common ubiquitous disease leading to a broad range of clinical presentations, from mild spontaneously resolving infections to severe complicated episodes requiring hospitalisation and intravenous therapies. ${ }^{1-3}$ Whereas this infection is fortunately benign in the vast majority of cases, it can lead to disseminated life-threatening diseases in unimmunised newborns contaminated around the time of delivery, especially in case of prematurity. On the contrary, VZV has been shown to only cause mild disease in babies born from previously immunised mothers who contracted the virus postnatally from infected family contacts. ${ }^{4-11}$

It has been demonstrated that the pattern and severity of child infection depends on the moment of contamination (before, around or after delivery), the maternal immunological status against VZV, the gestational age of the baby and the presence of other underlying conditions. ${ }^{6} 7 \mathrm{12}$ However, some confusion-and even fear-remains in the management of youngest infants after a contact with a varicella case mainly due to the unreliability of early clinical presentation in this age group, the significant risk of life-threatening complications in case of perinatal infection and the lack of therapeutic consensus. In daily practice, paediatricians and general practitioners tend too systematically refer to an infectious disease specialist and recommend hospitalisation only because of young patient's age rather than considering disease severity. ${ }^{13}$ Better knowledge of varicella natural history, as well as risk factors for disseminated disease and indications for therapy, is, therefore, mandatory not only to start early treatment in those who need it the most but also to avoid unnecessary hospitalisations and subsequent nosocomial complications in the others.

In this setting, we aim to offer short pragmatic recommendations for the management of newborns and infants who were proved to be in contact with VZV infected cases. After careful literature review, we propose specific therapeutic attitudes in different kinds of a situation defined according to the type and period of contamination of the baby as well as the maternal and infant medical status.

\section{STATE OF THE ART}

\section{Epidemiology and clinical presentation}

Varicella during pregnancy is a rare but potentially serious condition able to generate severe maternal and fetal disease as well as disseminated infection in newborns. According to a survey in the UK, its incidence turns around at least $1 / 2000$ live birth. ${ }^{11}$ As detailed in tables 1 and 2, clinical presentation and severity for the future newborn will depend on the moment where the mother contracted the virus in relation to the timing of the pregnancy. ${ }^{67}$ A maternal infection occurring during the first two trimesters of pregnancy can lead to congenital varicella, which is characterised by disseminated lesions of the skin, eyes, bones and central nervous system of the 
Table 1 Clinical presentation of mother and child varicella according to the timing of VZV acquisition during pregnancy (adapted from Sauerbrei $A$ and Wutzler P. J Perinatol $\left.2001 ; 21: 545^{6}\right)$

\begin{tabular}{|c|c|}
\hline $\begin{array}{l}\text { Timing of maternal } \\
\text { infection during } \\
\text { pregnancy }\end{array}$ & $\begin{array}{l}\text { Clinical patterns in mother, fetus } \\
\text { and newborn }\end{array}$ \\
\hline $\begin{array}{l}\text { Varicella in the } \\
20 \text { first weeks of } \\
\text { gestation }\end{array}$ & $\begin{array}{l}\text { Congenital varicella in } 2 \% \text { of } \\
\text { cases (fatality rate: } 30 \% \text { ) }\end{array}$ \\
\hline $\begin{array}{l}\text { Varicella in the third } \\
\text { trimester }\end{array}$ & $\begin{array}{l}\text { Maternal pneumonia in } 10 \%- \\
20 \% \text { of cases (fatality rate: } \\
10 \%)\end{array}$ \\
\hline $\begin{array}{l}\text { Varicella around } \\
\text { delivery } \\
\begin{array}{l}-\quad \geq 5-6 \text { days before } \\
-\quad \leq 4-5 \text { days before } \\
\text { to } 2 \text { days after }\end{array}\end{array}$ & $\begin{array}{l}\text { Neonatal varicella in } 20 \%-50 \% \\
\text { of cases } \\
\text { - } \text { Fatality rate } 0 \% \\
\text { - Fatality rate } 0 \%-3 \% \text { when } \\
\text { rash starts at } 0-4 \text { days of life } \\
\text { up to } 20 \% \text { when rash starts } \\
\text { at 5-12 days of life }\end{array}$ \\
\hline $\begin{array}{l}\text { Irrespective of timing } \\
-\quad \text { Maternal varicella }\end{array}$ & $\begin{array}{l}\text { Risk of intrauterine death or } \\
\text { zoster in the newborn (during } \\
\text { the first year of life) } \\
\text { No risk of severe infection for } \\
\text { mother/fetus/neonate }\end{array}$ \\
\hline
\end{tabular}

growing fetus. Congenital varicella will be unfortunately fatal in roughly $30 \%$ of the infected babies during the first month of life and the risk of embryopathy following congenital varicella is about $2 \%$ in survivors. ${ }^{14}$ Whether maternal varicella infection in the first 20 weeks of pregnancy increases the risk of miscarriage remains controversial $^{61415}$ (table 1).

On another hand, neonatal varicella occurs when the mother is infected during the three last weeks of pregnancy $^{6}$ (tables 1 and 2).

Table 2 Outcome without antiviral therapy after maternal or neonatal varicella according to the timing of infection around birth (adapted from Sauerbrei $A$ and Wutzler $P$. J Perinatol 2001;21:5456)

\begin{tabular}{|c|c|c|}
\hline \multirow[b]{2}{*}{ Day of rash onset } & \multicolumn{2}{|c|}{ Cases $(\mathrm{N}=136)$} \\
\hline & Survival & Death \\
\hline \multicolumn{3}{|l|}{ Mother } \\
\hline$\geq 5$ days before delivery $(n=57)$ & $\begin{array}{l}57 \\
(100 \%)\end{array}$ & 0 \\
\hline $\begin{array}{l}\leq 4 \text { days before to } 2 \text { days after delivery } \\
(n=79)\end{array}$ & $\begin{array}{l}65 \\
(82 \%)\end{array}$ & $\begin{array}{l}14 \\
(18 \%)\end{array}$ \\
\hline \multicolumn{3}{|l|}{ Newborn } \\
\hline $0-4$ days of life $(n=35)$ & $\begin{array}{l}34 \\
(97 \%)\end{array}$ & $1(3 \%)$ \\
\hline $5-10$ days of life $(n=47)$ & $\begin{array}{l}36 \\
(77 \%)\end{array}$ & $\begin{array}{l}11 \\
(23 \%)\end{array}$ \\
\hline
\end{tabular}

There are three ways of VZV mother-to-child transmission, defined as follows:

- Transplacental viremia.

- Direct contamination during delivery (skin lesions, blood, and so on)

- Postnatal contamination by respiratory droplets or skin contact with infected vesicles.

When acquired in utero, the severity of varicella disease in the newborn will be determined by the time between maternal infection and delivery (table 1): how long the time elapsing between those two and how important the rate of maternal-specific antibodies transferred through the placental membranes. These antibodies have been demonstrated to help in controlling of infection in the newborn. Several periods can, therefore, be distinguished, defined as follows:

- The highest risk period for the newborn corresponds to a VZV maternal infection contracted just around delivery ( -5 days to +2 days). In that case, the baby will be exposed to a high viral load but will have no time to acquire enough maternal protective antibodies. In the literature, contamination during this period is consequently associated with a significant rate of life-threatening disseminated disease in neonates (up to $20 \%-50 \%$ of transmission with a fatality rate of $20 \%$, table 2 ). The infection generally occurs between the 5th and 10th day of life. Fortunately, the fatality rate mentioned above is at present an overestimation since significant advances have been made in intensive cares as well as in antiviral treatments and immunotherapies from the time the studies mentioned above were made. ${ }^{16}$ This is well illustrated by the results from five other studies where no fatal case was recorded out of 231 babies with VZV perinatal transmission thanks to early administration of specific VZV immunoglobulins. ${ }^{17-21}$

- In fetus who were exposed earlier from 20 to 5 days before delivery, neonatal varicella can also develop, generally around the $0-4$ days of life (corresponding to 9-15 days after onset of maternal rash). Fortunately, in such cases, subsequent infection is generally mild to moderate, as attested by data from tables 1 and 2 (no fatal case reported).

- Irrespective of the timing of maternal VZV acquisition, infected newborns can further develop zoster during the first year of their life. Of note, a zoster infection in a pregnant woman is free of risk for the baby since protective maternal antibodies will be transmitted through placental transfer ${ }^{6}$ (table 1).

Considering the long incubation period of VZV (10-23 days), episode presented before the 10th-12th day of life can be considered as a prenatal infection, whereas postnatal acquisition is the most likely when infection starts from the 13th day of age onwards. In the absence of high prematurity, a varicella infection acquired postnatally during the first month of life will in the vast majority of cases lead to mild to moderate diseases. $^{67}$ Even in infants born from seronegative 
mothers, no life-threatening clinical presentations will generally be encountered as compared with perinatal acquisition just around the time of delivery. Whereas both groups are deprived from protective maternal antibodies, the difference observed in clinical pattern suggests a key role of the newborn cell-mediated immunity in controlling VZV disease. Newborn cell-mediated responses are likely insufficient to hinder haematogenous dissemination after transplacental spread but could hamper viral replication after transmission by the respiratory route. ${ }^{6} 14$ The importance of the infecting viral load could also partially contribute to this observation.

\section{Prevention and treatment}

\section{Immune globulins}

Efficacy of administration of specific immune globulins in preventing consequences of varicella in healthy subjects has been recognised since $1969 .{ }^{22}$ However, the role of VZV immune globulins in preventing neonatal infection remains insufficiently demonstrated in the scientific literature. Five studies of which only two were prospective but not randomised ${ }^{17-21}$ could be retrieved and concluded that administration of varicella zoster immune globulins (VZIG) to VZV exposed newborns can prevent roughly $50 \%$ of symptomatic cases and reduce the severity of infection among others. The most severe diseases in these series were recorded among neonates born within the 5 days of maternal eruption. However, some cases are published that describe serious and even fatal situations despite VZIG prophylaxis. $^{1123-26}$

Recommended VZIG doses administered through intramuscular injection are: ${ }^{2}$

- Newborn<2.0 kg: $125 \mathrm{U}$.

- Newborn>2.0 kg: $250 \mathrm{U}$.

Whereas VZIG is available and recommended in the USA, many European countries cannot easily benefit from such therapy, and therefore require alternatives to prevent neonatal varicella. Many European procedures, hence, include regular intravenous immune globulins (IVIG) $(400 \mathrm{mg} / \mathrm{kg}$ once) in combination or not with acyclovir. Efficacy of this treatment has been supported by a study assessing 15 newborns considered at high risk of severe presentation after a maternal infection occurring in the risky period (from 7 days before to 5 days after delivery) ${ }^{27}$ All of them received $500 \mathrm{mg} / \mathrm{kg}$ immediately after birth or after the infective contact, with or without intravenous acyclovir. Acyclovir was started 7 days after the first day of onset of maternal eruption and kept for 5 days. None of the 10 newborns receiving IVIG therapy plus intravenous acyclovir presented with symptomatic varicella. ${ }^{27}$

\section{Acyclovir}

No controlled clinical trials have evaluated the efficacy of acyclovir treatment in neonatal varicella. ${ }^{28}$ However, most experts recommend this drug in the management of newborn varicella disease since acyclovir is almost the only antiviral medication efficient against herpes viruses for which sufficient pharmacokinetic/dynamic data and safety profile are available in neonates. Recent studies with acyclovir have suggested that current dosing regimens may not result in therapeutic central nervous system concentrations. More frequent dosing may, therefore, be required for at term neonates. ${ }^{29}$

\section{PRACTICAL RECOMMENDATIONS FOR A NEWBORN/INFANT IN CONTACT WITH VZV}

Case scenario 1: the mother is the source of contamination 1a. Worst case scenario: mother starting varicella symptoms between $\mathrm{D}-5$ and $\mathrm{D}+2$ around delivery: perinatal infection

As detailed above, the prevalence of life-threatening disease when infection occurs in the period around delivery is the highest and justifies heavy protective measures and preventive therapy immediately after birth, even in a fully asymptomatic newborn. Timing of therapy is conditioned by the long period of incubation characterising VZV infection (viral dissemination and consequent rash occurring between 9 and 15 days after the infective contact, which is considered here to be the first day of maternal eruption).

\section{Therapeutic recommendations}

- Keep newborn and mother for at least 3 days hospitalised (with airborne and contact precautions for both).

- Treat the baby with either VZIG (see dosage above) or, if unavailable, IVIG $400 \mathrm{mg} / \mathrm{kg}$ as soon as possible within the first 48-96 hours after birth.

- If the child does not have any other comorbidity and is fully asymptomatic and the parents are reliable, mother and baby could leave the hospital between administration of immune globulins and acyclovir therapy.

- Treat the baby with intravenous acyclovir $30 \mathrm{mg} / \mathrm{kg} /$ day divided into three doses, from day 7 after the onset of maternal rash and administer during 10 days.

- In case, no peripheral venous access could be placed to give intravenous acyclovir despite several attempts, the antiviral treatment could be started orally pending the child is fully asymptomatic and remains under careful medical surveillance. A central line should only be recommended in case of clinical worsening.

- In the rare case, the newborn will develop varicella symptoms despite treatment, administer acyclovir for at least 3 weeks and search for underlying conditions (congenital immunodeficiency, metabolic disease, viral resistance, and so on).

1.b Mother starting varicella symptoms from $D+3$ to $D+28$ after delivery: postnatal infection

As detailed in tables 1 and 2, the risk for newborn infection is also high justifying preventive therapy but the risk of infection leading to severe disease is much lower. 


\section{Therapeutic recommendations}

- Treat the baby with acyclovir per os (PO) $80 \mathrm{mg} / \mathrm{kg} /$ day divided into four doses from day 7 after the onset of maternal rash and administer during 7-10 days.

- Indication and duration of hospitalisation (with airborne and contact precautions) should be discussed in each case depending on mother and child clinical status, parental compliance and social setting. If any doubt, hospitalisation with optimal medical surveillance are warranted during the risk period.

- In the rare case, the newborn will develop varicella symptoms despite preventive therapy, consideraccording to clinical evolution and severity-to hospitalise and switch to intravenous acyclovir for at least 3 weeks and search for underlying conditions (congenital immunodeficiency, metabolic disease, viral resistance, and so on).

\section{1.c Mother starting varicella symptoms from D-20 to D-6 before}

\section{delivery}

There are no published recommendations for this specific situation. It is common knowledge that such newborns can develop symptomatic varicella and even present with apparent skin lesions at birth. However, as presented in table 1 , the infection will be generally mild (no fatal case reported). Our expert opinion in such case would be to administer preventive therapy to prevent severe disease but to tailor it according to the clinical pattern, defined as follows:

- Keep newborn and mother for at least 3 days hospitalised (with airborne and contact precautions for both).

- Treat the baby with either VZIG (see dosage above) or, if unavailable, IVIG $400 \mathrm{mg} / \mathrm{kg}$ as soon as possible (within the first 48-96 hours after birth).

- If the child does not have any other comorbidity and is fully asymptomatic and the parents are reliable, mother and baby could leave the hospital after administration of immune globulins. If any doubt, hospitalisation with optimal medical surveillance are warranted during the risk period (first week of life).

- If vesicles are present at birth or appear, add acyclovir PO $80 \mathrm{mg} / \mathrm{kg} /$ day divided into four doses and maintain over 7 days (according to clinical evolution) and hospitalise the baby for surveillance. Duration of hospitalisation (with airborne and contact precautions) should be discussed in each case depending on mother and child clinical status, parental compliance and social setting.

\section{Case scenario 2: high prematurity}

Similar recommendations to Section 1. a should be applied in case of contact with varicella from any origin (maternal or not) in the following groups:

- Extremely preterm babies (gestational age (GA)<28 weeks) regardless of the maternal VZV serological status.
- Very-preterm (GA 28-32 weeks) and moderate-preterm to late-preterm (GA 32-37 weeks) babies born from an unimmunised mother.

Case scenario 3: asymptomatic newborn in contact with VZV from any infected subject

Since transmission of VZV occurs not only through direct skin contact with vesicles but mainly through the airborne route (droplets nuclei), an 'infective contact' with a VZV-infected person is defined as having any close contact together, such as a close indoor contact (eg, in the same room) or face-to-face contact. However, experts differ in their opinion about the duration of the infective contact: whereas some suggest $5 \mathrm{~min}$, others require up to 1 hour. $^{2}$ Of note, this is different for zoster-infected person with which only a skin contact with the lesions will be a source of contamination. A VZV-infected subject is considered potentially contaminant until all his skin vesicles are crusted.

In this scenario, the mother immunological status against VZV will determine the risk of infection and disease in her baby.

The first step is careful anamnesis of the mother to confirm or not history of varicella. If no previous varicella could be guaranteed, then a serological testing should be done to the mother and the baby carefully observed pending the results.

- The mother is proved seropositive:

- Very low risk of disease in the baby.

- No treatment should be provided.

- Observance of the baby at home and encourage parents to come back if any clinical sign or symptom appears in the 2 weeks after contact.

- If symptoms or signs of varicella, refer to the section Case scenario 4.

- The mother is proved seronegative or refuses testing:

- Treat the baby with acyclovir PO $80 \mathrm{mg} / \mathrm{kg} /$ day divided into four doses to start 7 days after infective contact and administer during 7 days.

- Careful surveillance of the baby during the risk period. Indication and duration of hospitalisation (with airborne and contact precautions) should be discussed in each case depending on child clinical status, parental compliance and social setting. If any doubt, hospitalisation with optimal medical surveillance are warranted during the risk period.

- If symptoms or signs of varicella, refer to the section Case scenario 4.

Case scenario 4: infant $<1$ month of age presenting with clinical signs of varicella

- First of all, in every newborn presenting with fever and varicella vesicles, the presence of viral eruption should not automatically rule out a concomitant bacterial infection and precaution should prevail. A full workup to exclude bacterial late-onset infection should be realised depending on baby's clinical and biological status: 
- In every newborn with fever $>38.5^{\circ}$ or elevated C-Reactive Protein (CRP) or altered clinical status:

- Perform full microbiological workup (including lumbar puncture)

- Treat with broad intravenous antibiotics in addition to acyclovir (see below) until obtaining culture results.

- In case a source of bacterial infection will be identified, consider a switch to narrow spectrum antibiotic.

- If the baby presents with a confirmed varicella diagnosis and fever $<38.5^{\circ} \mathrm{C}$, no inflammatory syndrome as well as no altered clinical status after examination by a senior paediatrician:

- Hospitalise under careful medical surveillance without extra invasive workup/antibiotic treatment.

- Treat with acyclovir (see below).

- Add other exams or treatment if new symptoms/signs or worsening.

- As for varicella treatment, administration of acyclovir is always recommended. Way of administration depends on mother immunological status against VZV:

- Mother with a confirmed medical history of varicella:

- Low risk of severe varicella disease.

- Treat the baby with acyclovir PO $80 \mathrm{mg} / \mathrm{kg} /$ day divided into four doses.

- Hospitalisation according to clinical presentation (fever, altered general status, severe eruption, suspected bacterial superinfection, and so on) and social setting (parental incompliance and so on).

- Mother with no history of varicella or status unknown:

- Mandatory hospitalisation.

- Treat the baby with acyclovir for a minimum of 7 days. Start with acyclovir intravenous $30 \mathrm{mg} /$ $\mathrm{kg}$ /day divided into three doses for moderate to severe cases and switch to acyclovir $\mathrm{PO}$ as soon as observing significant clinical improvement. Treat directly with acyclovir PO $80 \mathrm{mg} / \mathrm{kg} /$ day divided into four doses for mild clinical presentations.

\section{Case scenario 5: infant $>1$ month of age presenting with clinical signs of varicella}

In infants aged $>1$ month having no underlying medical condition and presenting with uncomplicated varicella, the administration of acyclovir is not systematically recommended, irrespective of the mother VZV immunological status. Decision of prescribing an antiviral treatment should be based on the clinical pattern and severity of infection (child general status, importance of rash, presence of neurological complications or superinfection, and so on).
Similarly to what detailed in the section Case scenario 4, the presence of a varicella at admission does not exclude a concomitant bacterial infection so that febrile children should be managed carefully in searching other possible causes of fever when appropriate.

\section{DO NOT FORGET FAMILY VACCINATION...}

All seronegative subjects in contact with a newborn with VZV infection should be offered immunisation (two doses with a minimum of 6 weeks between injections) unless contraindicated (infants and immunodeficient persons) within the 72 hours of the infectious contact. This recommendation is particularly important for adolescents and adults who are at major risk of severe disease presentation.

\section{CONCLUSIONS}

Despite numerous advances over the last decades, management of varicella in the youngest remains a challenge in daily practice and quality studies on this topic are limited.

Whereas experts agree that contamination around delivery deserves aggressive preventive therapy regarding the risk of life-threatening disease in newborns, attitudes in other situations involving postnatal infections are eminently variable and source of confusion.

In order to avoid unnecessary hospitalisations and treatments but considering the likelihood of severe infectious episode at some points, we suggest the management of a newborn after a VZV contact should not be driven only by the age group but rather tailored case by case following careful assessment of the type of viral transmission, the risk factors of serious disease and above all the baby clinical status.

Contributors Both PL and SB contributed to review the literature, edited the guidelines and wrote the manuscript.

Funding The authors have not declared a specific grant for this research from any funding agency in the public, commercial or not-for-profit sectors.

Competing interests None declared.

Patient consent for publication Not required.

Provenance and peer review Not commissioned; externally peer reviewed.

Open access This is an open access article distributed in accordance with the Creative Commons Attribution Non Commercial (CC BY-NC 4.0) license, which permits others to distribute, remix, adapt, build upon this work non-commercially, and license their derivative works on different terms, provided the original work is properly cited, appropriate credit is given, any changes made indicated, and the use is non-commercial. See: http://creativecommons.org/licenses/by-nc/4.0/.

\section{REFERENCES}

1. Heininger U, Seward JF. Varicella. The Lancet 2006;368:1365-76.

2. Varicella Zoster Virus infections. Red book. 2015 report of the Committee on infectious diseases. American Academy of Pediatrics, 2015: 846-60.

3. Blumental S, Sabbe M, Lepage P, et al. Varicella paediatric hospitalisations in Belgium: a 1-year national survey. Arch Dis Child 2016;101:16-22.

4. Preblud SR, Bregman DJ, Vernon LL. Deaths from varicella in infants. The Pediatric Infectious Disease Journal 1985;4:503-7. 
5. Prober CG, Gershon AA, Grose C, et al. Consensus: varicella-zoster infections in pregnancy and the perinatal period. Pediatr Infect Dis $J$ 1990;9:865-9.

6. Sauerbrei A, Wutzler P. Neonatal varicella. J Perinatol 2001;21:545-9.

7. Lamont RF, Sobel JD, Carrington D, et al. Varicella-zoster virus (chickenpox) infection in pregnancy. BJOG 2011;118:1155-62.

8. Brunell PA. Fetal and neonatal varicella-zoster infections. Semin Perinatol 1983;7:47-56.

9. Smith CK, Arvin AM. Varicella in the fetus and newborn. Semin Fetal Neonatal Med 2009;14:209-17.

10. Gershon AA, Raker R, Steinberg S, Todf-Ostein B, et al. Antibody to varicella-zoster virus in parturient women and their offspring during the first year of life. Pediatrics 1976;58:692-6.

11. Tebruegge M, Pantazidou A, Curtis N. Towards evidence based medicine for paediatricians. How effective is varicella-zoster immunoglobulin (VZIG) in preventing chickenpox in neonates following perinatal exposure? Arch Dis Child 2009;94:559-61.

12. Baba K, Yabuuchi H, Takahashi M, et al. Immunologic and epidemiologic aspects of varicella infection acquired during infancy and early childhood. The Journal of Pediatrics 1982;100:881-5.

13. Lécuyer A, Levy C, Gaudelus J, et al. Hospitalization of newborns and young infants for chickenpox in France. Eur J Pediatr 2010;169:1293-7.

14. Sauerbrei A, Wutzler P. Herpes simplex and varicella-zoster virus infections during pregnancy: current concepts of prevention, diagnosis and therapy. Part 2: Varicella-zoster virus infections. Med Microbiol Immunol 2007;196:95-102.

15. Pastuszak AL, Levy M, Schick B, et al. Outcome after maternal varicella infection in the first 20 weeks of pregnancy. $N$ Engl J Med 1994;330:901-5.

16. Meyers JD. Congenital varicella in term infants: risk reconsidered. Journal of Infectious Diseases 1974;129:215-7.

17. Miller E, Cradock-Watson TE, Ridehalgh MS. Outcome in newborn babies given anti-varicella-zoster immunoglobulin after perinatal maternal infection with varicella-zoster virus. The Lancet 1989;334:371-3.

18. Carter P, Duffy P, Lloyd DJ. Neonatal varicella infection. The Lancet 1986;328:1459-60.

19. Hanngren K, Grandien M, Granström G. Effect of zoster immunoglobulin for varicella prophylaxis in the newborn. Arch. Of Physiology \& Biochem. 1985;17:343-7.

20. Evans EB, Pollock TM, Cradock-Watson JE, et al. Human antichickenpox immunoglobulin in the prevention of chickenpox. The Lancet 1980;315:354-6.

21. Winsnes R. Efficacy of zoster immunoglobulin in prophylaxis of varicella in high-risk patients. Acta Paediatrica 1978;67:77-82.

22. Brunell PA, Ross A, Miller LH, et al. Prevention of varicella by zoster immune globulin. N Engl J Med 1969;280:1191-4.

23. Bakshi SS, Miller TIMC, Kaplan M, et al. Failure of varicella-zoster immunoglobulin in modification of severe congenital varicella. The Pediatric Infectious Disease Journal 1986;5:699-702.

24. Reynolds L, Struik S, Nadel S. Neonatal varicella: varicella zoster immunoglobulin (VZIG) does not prevent disease. Archives of Disease in Childhood - Fetal and Neonatal Edition 1999;81:F69-F70.

25. Holland $P$, Isaacs $D$, Moxon $E R$. Fatal neonatal varicella infection. The Lancet 1986;328.

26. King SM, Gorensek M, Ford-Jones EL, et al. Fatal varicella-zoster infection in a newborn treated with varicella-zoster immunoglobulin. The Pediatric Infectious Disease Journal 1986;5:588-9.

27. Huang Y-C, Lin T-Y, Lin Y-J, et al. Prophylaxis of intravenous immunoglobulin and acyclovir in perinatal varicella. Eur J Pediatr 2001;160:91-4.

28. Whitley RJ. The use of antiviral drugs during the neonatal period. Clinics in Perinatology 2012;39:69-81.

29. Roberts JK, Stockmann C, Constance JE, et al. Pharmacokinetics and pharmacodynamics of antibacterials, antifungals, and antivirals used most frequently in neonates and infants. Clin Pharmacokinet 2014;53:581-610. 